\title{
Numerical Analysis and Transformative Predictions of Fractional Order Epidemic Model during COVID-19 Pandemic: A Critical Study from Bangladesh
}

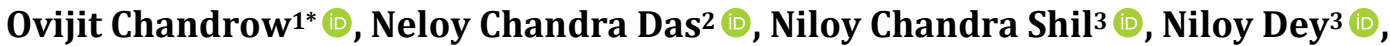 \\ Md. Tareque Rahaman ${ }^{4}$ \\ ${ }^{1}$ Department of Physics, Shahjalal University of Science and Technology, Sylhet, Bangladesh \\ ${ }^{2}$ Department of Mechanical Engineering, Shahjalal University of Science and Technology, Sylhet, Bangladesh \\ ${ }^{3}$ Department of Computer Science and Engineering, Daffodil International University, Dhaka, Bangladesh \\ ${ }^{4}$ Department of Textile Engineering, Mawlana Bhashani Science and Technology University, Tangail, Bangladesh \\ Email: *ecchaovi@gmail.com
}

How to cite this paper: Chandrow, O., Das, N.C., Shil, N.C., Dey, N. and Rahaman, M.T. (2021) Numerical Analysis and Transformative Predictions of Fractional Order Epidemic Model during COVID-19 Pandemic: A Critical Study from Bangladesh. Journal of Applied Mathematics and Physics, 9, 2258-2276.

https://doi.org/10.4236/jamp.2021.99144

Received: July 24, 2021

Accepted: September 13, 2021

Published: September 16, 2021

Copyright $\odot 2021$ by author(s) and Scientific Research Publishing Inc. This work is licensed under the Creative Commons Attribution International License (CC BY 4.0).

http://creativecommons.org/licenses/by/4.0/ (c) (i) Open Access

\begin{abstract}
The COVID-19 pandemic is a curse and a threat to global health, development, the economy, and peaceful society because of its massive transmission and high rates of mutation. More than 220 countries have been affected by COVID-19. The world is now facing a drastic situation because of this ongoing virus. Bangladesh is also dealing with this issue, and due to its dense population, it is particularly vulnerable to the spread of COVID-19. Recently, many non-linear systems have been proposed to solve the SIR (Susceptible, Infected, and Recovered) model for predicting Coronavirus cases. In this paper, we have discussed the fractional order SIR epidemic model of a non-fatal disease in a population of a constant size. Using the Laplace Adomian Decomposition method, we get an approximate solution to the model. To predict the dynamic transmission of COVID-19 in Bangladesh, we provide a numerical argument based on real data. We also conducted a comparative analysis among susceptible, infected, and recovered people. Furthermore, the most sensitive parameters for the Basic Reproduction Number $\left(R_{0}\right)$ are graphically presented, and the impact of the compartments on the transmission dynamics of the COVID-19 pandemic is thoroughly investigated.
\end{abstract}

\section{Keywords}

COVID-19, Bangladesh, Fractional Order SIR Model, Laplace Adomian Decomposition Method, BRN 


\section{Introduction}

In December 2019, the virus resurfaced in Wuhan, China, prompting the World Health Organization (WHO) to proclaim COVID-19 as a pandemic [1] [2]. The COVID-19 outbreak is causing havoc in people's personal lives all over the world, as well as a dire economic and social situation. This RNA-based virus is a member of the family of Coronaviridae that causes Severe Acute Respiratory Syndrome (SARS) [3] [4]. The other viruses in this family have caused local outbreaks in the past. The Coronavirus (COVID-19) has caused greater morbidity and mortality than Severe Acute Respiratory Syndrome coronavirus (SARS-CoV) and Middle East Respiratory Syndrome Coronavirus (MERS-CoV) [5]. Some scientists believe that this virus infects the human body in the medium of a serpent or bat. Severe Acute Respiratory Syndrome Coronavirus-2 (SARS-CoV-2), the virus that causes COVID-19, is phylogenetically the most closely related to bat coronaviruses, with a $96 \%$ similarity to the virus found in horseshoe bats [6] [7] [8]. Coronaviruses have the ability to change their viability, which is one of the reasons they are so contagious. Initially, the common symptoms were fever, cough, dyspnea, myalgia or fatigue, headache, hemoptysis, diarrhea, and acute respiratory distress syndrome [9] [10] [11] [12]. Because of the severity, most countries have halted all activities as a precaution, and they encourage people to stay at home and avoid crowds. Experts recommend flattening it out with social distance. As a result of the new lawsuit, more than $1 / 3$ of the people worldwide were on lockdown at the moment.

On March 8, 2020, the Institute of Epidemiology, Disease Control, and Research (IEDCR) reported the first three confirmed cases of COVID-19 in Bangladesh. Bangladesh's government immediately declared a national lockdown to combat the coronavirus outbreak. Despite the fact that preventing the virus is impossible, the Bangladesh government has taken numerous steps to neutralize it [13]. Bangladesh is the most densely populated country in the world. As a result, it was the most dangerous region to spread COVID-19, as was proven after the second wave hit the country. The case rate was downcast in 2020, but when the second wave hit the country, the rate of cases surged. And yet, this pattern of cases continues [14].

The confining healthcare system is the major cause of the spread of the virus in Bangladesh. Bangladesh has experienced the most ICU crisis and oxygen crisis in the medical sector [15] [16] [17]. Many people are currently dying without getting oxygen and necessary treatment. IEDCR has confirmed that the new variants are caused by the ongoing lockdown. In Bangladesh, a total of five variants have been found in different districts. The most recent variant, known as Delta variants (B.1.617.2), came from India, a neighboring country to Bangladesh. The rest of the variants are the UK (B.1.1.7), South Africa (B.1.351), Nigeria (B.1.525), and Brazilian (P1) variants of the Coronavirus [18]. None of them are double mutants. That means it has the odds of wreaking havoc in Bangladesh. The COVID-19 pandemic has had a significant impact on household and indi- 
vidual earnings, with around $13 \%$ of the population becoming unemployed, with women in informal employment being more likely than men to have their working hours reduced in Bangladesh. Meanwhile, the Bangladesh Institute of Development Studies (BIDS) claims that national poverty will rise by 25.13 percent [19] [20] [21].

In this paper, we chose the fractional order Susceptible, Infected, and Recovered (SIR) model to predict the situation in Bangladesh. Because, many scientists have demonstrated over the last few decades that fractional models can more accurately explain natural phenomena than integer-order differential equations in modeling biological, economic, and social systems where memory effects are important [22]. It is critical to assess the disease's potential future impacts through an understanding of its dynamics, forecasting future trends, and planning effective control strategies to develop competent economic activity guidelines and public health policies. Our efforts might be able to predict the COVID-9 pandemic situation, which would stir up awareness among the people.

\section{An Overview of SIR Epidemic Model}

Our aim is to predict the future conditions of Coronavirus (COVID-19) cases in Bangladesh and, if possible, control the spread of diseases. In this case, we have described the SIR model [23]. In this model, the fixed population consists of three compartments. The descriptions of the parameters used to describe this model can be found in Table 1, where $S(t)$ recounts the susceptible people that are not infected by the disease. $I(t)$ recounts the infected people that can spread the disease by contiguity with susceptible class. $R(t)$ recounts the recovered people having a cure from the disease.

$$
\begin{aligned}
& \frac{\mathrm{d} S(t)}{\mathrm{d} t}=-\frac{\eta}{N} S(t) I(t) \\
& \frac{\mathrm{d} I(t)}{\mathrm{d} t}=\frac{\eta}{N} S(t) I(t)-\mu I(t) \\
& \frac{\mathrm{d} R(t)}{\mathrm{d} t}=\mu I(t)
\end{aligned}
$$

It is assumed that the population size of this model is constant and the total population is stated as,

$$
N(t)=S(t)+I(t)+R(t)
$$

Table 1. Parameters descriptions.

\begin{tabular}{cc}
\hline Notations & Description \\
\hline$S(t)$ & The number of Susceptible people in time $t$ \\
$I(t)$ & The number of Infected people in time $t$ \\
$R(t)$ & The number of Recovered people in time $t$ \\
$\eta$ & The rate of infection \\
$\mu$ & The rate of recovery \\
\hline
\end{tabular}


The basic description of model is interpreted in Figure 1. The underlying peculiarity of the model is,

1) Susceptible people are functioned to the infected people with the rate of $\eta$.

2) Then, the infected people are immensely acted to the recovered people with the rate of $\mu$.

3) The recovered people regress to the susceptible class after losing immunity from the diseases.

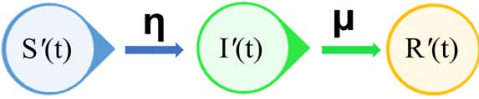

Figure 1. Working diagram of SIR model.

The transition rate between susceptible class and the infected class is $\eta I(t)$, which contemplates the probability of getting the disease in a contact between a susceptible and an infectious subject [24]. The transition rate between Infected and recovered class is $\mu$ which indicates the rate of recovery. All the parameters are positive. The range of $\eta$ and $\mu$ is $0 \leq \eta \leq 1$ and $0 \leq \mu \leq 1$ respectively. It is known that $S(t), I(t), R(t)$ are fraction of the total population. We may write,

$$
S^{\prime}(t)+I^{\prime}(t)+R^{\prime}(t)=1
$$

where, $S^{\prime}(t)=\frac{S(t)}{N}, I^{\prime}(t)=\frac{I(t)}{N}, R^{\prime}(t)=\frac{R(t)}{N}$.

Based on the assumptions and model diagram, we can define a system of differential equation as follows,

$$
\begin{aligned}
& \frac{\mathrm{d} S^{\prime}(t)}{\mathrm{d} t}=-\eta S^{\prime}(t) I^{\prime}(t) \\
& \frac{\mathrm{d} I^{\prime}(t)}{\mathrm{d} t}=\eta S^{\prime}(t) I^{\prime}(t)-\mu I^{\prime}(t) \\
& \frac{\mathrm{d} R^{\prime}(t)}{\mathrm{d} t}=\mu I^{\prime}(t)
\end{aligned}
$$

with subject to the initial conditions,

$$
\begin{aligned}
& S^{\prime}(0)=n_{1} \geq 0 \\
& I^{\prime}(0)=n_{2} \geq 0 \\
& R^{\prime}(0)=n_{3} \geq 0
\end{aligned}
$$

Remark-1: (Classical case) Initial conditions hold,

If, $S^{\prime}(t)>0, I^{\prime}(0)>0$, then

$$
\begin{gathered}
\frac{\mathrm{d} S^{\prime}(t)}{\mathrm{d} t}=-\eta S^{\prime}(t) I^{\prime}(t)<0, \forall S^{\prime}(t)>0, I^{\prime}(0)>0 \\
\frac{\mathrm{d} I^{\prime}(t)}{\mathrm{d} t}=I^{\prime}(t)\left[\eta S^{\prime}(t)-\mu\right]
\end{gathered}
$$

Combining Equation (2.3a) and Equation (2.3b),

$$
S^{\prime}(t)-\frac{\mu}{\eta}=0
$$


So,

$$
\frac{\mathrm{d} I^{\prime}(t)}{\mathrm{d} t}<0, \text { if } S^{\prime}(t)<\frac{\mu}{\eta}
$$

The direction diagram can be defined as, $\frac{\mathrm{d} I^{\prime}(t)}{\mathrm{d} t}>0$, if, $S^{\prime}(t)>\frac{\mu}{\eta}$. Now, we calculate the trajectories and get,

$$
I^{\prime}(t)=-S^{\prime}(t)+\frac{\mu}{\eta} \log S^{\prime}(t)+k
$$

So, the taken initial conditions are,

(If),

$$
\begin{gathered}
S^{\prime}(t) \rightarrow 0, I^{\prime}(t) \rightarrow-\infty \\
S^{\prime}(t) \rightarrow+\infty, I^{\prime}(t) \rightarrow-\infty
\end{gathered}
$$

From the above consultation, we obtain three commentaries,

1) If $S^{\prime}(0)$ is greater than $\frac{\mu}{\eta}$, the pandemic will occur.

2) If $S^{\prime}(0)$ is less than $\frac{\mu}{\eta}$, the disease will dig out.

3) If $\frac{\eta S^{\prime}(0)}{\mu}>1$, then the number of infected people will be increased enormously.

Remark-2: The change in the rate of the susceptible class to the infected class is $\eta$ and it moves from $S^{\prime}(t)$ to $I^{\prime}(t)$ (Figure 2). After a certain time, the susceptible people will be zero and remain unchanged. Susceptible people will be

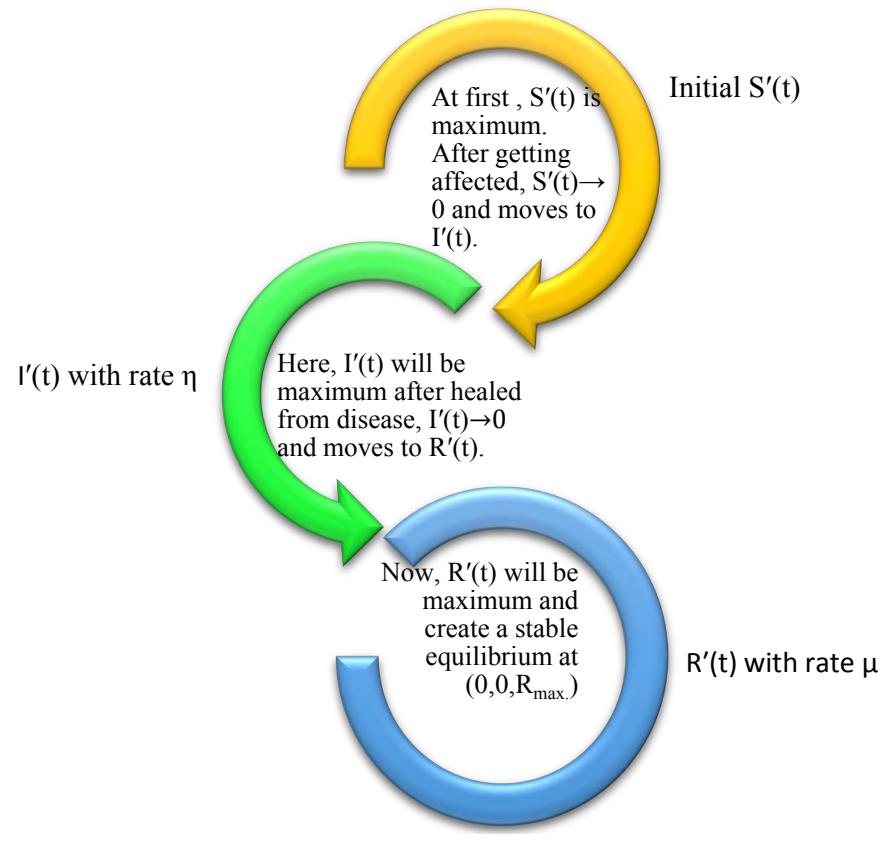

Figure 2. Working diagram of the SIR model shows how disease reaches a stable equilibrium point. 
affected by the transmission of the virus that moves to infected people. After that, the infected class will move $I^{\prime}(t)$ to $R^{\prime}(t)$. Finally, the number of recovered people will increase with the rate of $\mu$ and when the number of infected people tends to zero, the recovered people will get the maximum value as well. And the total features reach the stable equilibrium point at $\left(0,0, R_{\max }\right)$.

Remark-3: The nature of the SIR model is discrete because the maximum data is collected and, that provides a prompt way to compare with the output data of the model. In this model, the time dependent variables are $S^{\prime}, I^{\prime}$ and $R^{\prime}$. For measuring purposes, the whole data will be in the time domain. In this paper, we have collected data from different sources which may be weekly or daily for fast spreading epidemics like COVID-19. The compartments in the model will be estimated. After estimating the parameters, they can be easily determined in continuous form, which is more straightforward for numerical investigation.

\section{Preliminaries}

Here, we propound some basic definitions related to fractional calculus (see e.g. [25]).

Definition 3.1: The Riemann-Liouville (RL) fractional integration of order $\theta$ is defined as,

$$
\begin{gathered}
\left(Y_{t_{o}}^{\theta} p\right)=\frac{1}{\Gamma(\theta)} \int_{t_{0}}^{t}(t-s)^{\theta-1} p(s) \mathrm{d} s, \theta>0, t>t_{0} \\
\left(Y_{t_{o}}^{0} p\right)=p(t)
\end{gathered}
$$

It is difficult to get the solution of RL derivatives because the constant of RL derivatives is not zero. To make it easier and more comfortable, we will use Caputo's definition of RL derivatives in the light of Definition 3.1.

Definition 3.2: RL and Caputo fractional derivatives of order $\theta$ can be defined as follows,

$$
\begin{aligned}
& D^{\theta} p(t)=D^{n}\left(Y^{n-\theta} p(t)\right) \\
& D_{*}^{\theta} p(t)=Y^{n-\theta}\left(D^{n} p(t)\right)
\end{aligned}
$$

where, $n-1<\theta \leq n, n \in \mathbb{N}$.

Definition 3.3: Laplace transform of the Caputo derivative is defined as,

$$
L\left\{D^{\theta} p(t)\right\}=s^{\theta} p(s)-\sum_{k=0}^{n-1} s^{\theta-k-1} p^{k}(0)
$$

when, $n-1<\theta<n, \quad n \in \mathbb{N}$.

\section{Mathematical Modelling and Solution of the Fractional Order SIR Model}

The Laplace Adomian Decomposition method [26] [27] [28] is used to find the solution to the fractional order SIR model. This method is simple to use, and the resulting series is convergent easily compared with other methods. Applying the 
Laplace transform on both sides of Equation (2.2), the system of differential equations is converted into a system of algebraic expressions,

$$
\begin{aligned}
& L\left\{D^{\theta_{1}} S^{\prime}(t)\right\}=-\eta L\left\{S^{\prime}(t) I^{\prime}(t)\right\} \\
& L\left\{D^{\theta_{2}} I^{\prime}(t)\right\}=\eta L\left\{S^{\prime}(t) I^{\prime}(t)\right\}-\mu L\left\{I^{\prime}(t)\right\} \\
& L\left\{D^{\theta_{3}} R^{\prime}(t)\right\}=\mu L\left\{I^{\prime}(t)\right\}
\end{aligned}
$$

The known Laplace transform property is,

$$
L\left\{D^{\theta} p(t)\right\}=s^{\theta} L\{P(t)\}-s^{\theta-1} p(0)
$$

Using the Laplace transform property,

$$
\begin{aligned}
& s^{\theta_{1}} L\left\{S^{\prime}(t)\right\}-s^{\theta_{1}-1} S^{\prime}(0)=-\eta L\left\{S^{\prime}(t) I^{\prime}(t)\right\} \\
& s^{\theta_{2}} L\left\{I^{\prime}(t)\right\}-s^{\theta_{2}-1} I^{\prime}(0)=\eta L\left\{S^{\prime}(t) I^{\prime}(t)\right\}-\mu L\left\{I^{\prime}(t)\right\} \\
& s^{\theta_{3}} L\left\{R^{\prime}(t)\right\}-s^{\theta_{3}-1} R^{\prime}(0)=\mu L\left\{I^{\prime}(t)\right\}
\end{aligned}
$$

From Equation (2.3), we obtain,

$$
\begin{aligned}
& L\left\{S^{\prime}(t)\right\}=\frac{S^{\prime}(0)}{s}-\frac{\eta}{s^{\theta_{1}}} L\left\{S^{\prime}(t) I^{\prime}(t)\right\} \\
& L\left\{I^{\prime}(t)\right\}=\frac{I^{\prime}(0)}{s}+\frac{\eta}{s^{\theta_{2}}} L\left\{S^{\prime}(t) I^{\prime}(t)\right\}-\frac{\mu}{s^{\theta_{2}}} L\left\{I^{\prime}(t)\right\} \\
& L\left\{R^{\prime}(t)\right\}=\frac{R^{\prime}(0)}{s}+\frac{\mu}{s^{\theta_{3}}} L\left\{I^{\prime}(t)\right\}
\end{aligned}
$$

The method presumes the solution as an infinite series,

$$
\begin{aligned}
& S^{\prime}(t)=\sum_{i=0}^{\infty} S_{i}^{\prime}(t) \\
& I^{\prime}(t)=\sum_{i=0}^{\infty} I_{i}^{\prime}(t) \\
& R^{\prime}(t)=\sum_{i=0}^{\infty} R_{i}^{\prime}(t)
\end{aligned}
$$

Decomposing the non-linear part $S^{\prime}(t) I^{\prime}(t)$ as,

$$
S^{\prime}(t) I^{\prime}(t)=\sum_{i=0}^{\infty} X_{i}(t)
$$

where $X_{i}$ treats as the Adomian polynomials which is described as,

$$
X_{i}=\frac{1}{i !} \frac{\mathrm{d}^{i}}{\mathrm{~d} \lambda^{i}}\left[\sum_{j=0}^{i} \lambda^{j} S_{j}^{\prime}(t) \sum_{j=0}^{i} \lambda^{j} I_{j}^{\prime}(t)\right]
$$

Expanding Equation (4.7), further, the following polynomials are,

$$
\begin{aligned}
& X_{0}=S_{0}^{\prime}(t) I_{0}^{\prime}(t) \\
& X_{1}=S_{0}^{\prime}(t) I_{1}^{\prime}(t)+S_{1}^{\prime}(t) I_{0}^{\prime}(t) \\
& X_{2}=2 S_{0}^{\prime}(t) I_{2}^{\prime}(t)+2 S_{1}^{\prime}(t) I_{1}^{\prime}(t)+2 S_{2}^{\prime}(t) I_{0}^{\prime}(t)
\end{aligned}
$$

And so on.

Substituting Equation (4.5) and Equation (4.6), into Equation (4.4), 


$$
\begin{aligned}
& L\left\{\sum_{i=0}^{\infty} S_{i}^{\prime}(t)\right\}=\frac{S^{\prime}(0)}{s}-\frac{\eta}{s^{\theta_{1}}} L\left\{\sum_{i=0}^{\infty} X_{i}(t)\right\} \\
& L\left\{\sum_{i=0}^{\infty} I_{i}^{\prime}(t)\right\}=\frac{I^{\prime}(0)}{s}+\frac{\eta}{s^{\theta_{2}}} L\left\{\sum_{i=0}^{\infty} S_{i}^{\prime}(t) \sum_{i=0}^{\infty} I_{i}^{\prime}(t)\right\}-\frac{\mu}{s^{\theta_{2}}} L\left\{\sum_{i=0}^{\infty} I_{i}^{\prime}(t)\right\} \\
& L\left\{\sum_{i=0}^{\infty} R_{i}^{\prime}(t)\right\}=\frac{R^{\prime}(0)}{s}+\frac{\mu}{s^{\theta_{3}}} L\left\{\sum_{i=0}^{\infty} I_{i}^{\prime}(t)\right\}
\end{aligned}
$$

Comparing the both sides of Equation (4.9),

$$
\begin{aligned}
L\left\{S_{0}^{\prime}(t)\right\} & =\frac{S^{\prime}(0)}{s}=\frac{n_{1}}{s} \\
L\left\{S_{1}^{\prime}(t)\right\} & =-\frac{\eta}{s^{\theta_{1}}} L\left\{X_{0}(t)\right\} \\
L\left\{S_{2}^{\prime}(t)\right\} & =-\frac{\eta}{s^{\theta_{1}}} L\left\{X_{1}(t)\right\} \\
\vdots & \\
L\left\{S_{i+1}^{\prime}(t)\right\} & =-\frac{\eta}{s^{\theta_{1}}} L\left\{X_{i}(t)\right\}
\end{aligned}
$$

Similarly,

$$
\begin{aligned}
& L\left\{I_{0}^{\prime}(t)\right\}=\frac{I^{\prime}(0)}{s}=\frac{n_{2}}{s} \\
& \begin{aligned}
L\left\{I_{1}^{\prime}(t)\right\}= & \frac{\eta}{s^{\theta_{2}}} L\left\{X_{0}\right\}-\frac{\mu}{s^{\theta_{2}}} L\left\{I_{0}^{\prime}(t)\right\} \\
L\left\{I_{2}^{\prime}(t)\right\}= & \frac{\eta}{s^{\theta_{2}}} L\left\{X_{1}\right\}-\frac{\mu}{s^{\theta_{2}}} L\left\{I_{1}^{\prime}(t)\right\} \\
& \vdots
\end{aligned} \\
& L\left\{I_{i+1}^{\prime}(t)\right\}=\frac{\eta}{s^{\theta_{2}}} L\left\{X_{i}\right\}-\frac{\mu}{s^{\theta_{2}}} L\left\{I_{i}^{\prime}(t)\right\}
\end{aligned}
$$

Finally,

$$
\begin{aligned}
L\left\{R_{0}^{\prime}(t)\right\} & =\frac{R^{\prime}(0)}{s}=\frac{n_{3}}{s} \\
L\left\{R_{1}^{\prime}(t)\right\} & =\frac{\mu}{s^{\theta_{3}}} L\left\{I_{0}^{\prime}(t)\right\} \\
L\left\{R_{2}^{\prime}(t)\right\} & =\frac{\mu}{s^{\theta_{3}}} L\left\{I_{1}^{\prime}(t)\right\} \\
\vdots & \\
L\left\{R_{i+1}^{\prime}(t)\right\} & =\frac{\mu}{s^{\theta_{3}}} L\left\{I_{i}^{\prime}(t)\right\}
\end{aligned}
$$

Taking the inverse Laplace transform of Equation (4.10), Equation (4.11), Equation (4.12) and envisaging the first few terms yields,

For susceptible people,

$$
\begin{aligned}
& S_{0}^{\prime}(t)=n_{1} \\
& S_{1}^{\prime}(t)=\frac{-\eta n_{1} n_{2}}{\Gamma\left(\theta_{1}+1\right)} t^{\theta_{1}} \\
& S_{2}^{\prime}(t)=\frac{\eta^{2} n_{1} n_{2}^{2}}{\Gamma\left(2 \theta_{1}+1\right)} t^{2 \theta_{1}}-\frac{\eta n_{1}\left(\eta n_{1} n_{2}-\mu n_{2}\right)}{\Gamma\left(\theta_{1}+\theta_{2}+1\right)} t^{\left(\theta_{1}+\theta_{2}\right)}
\end{aligned}
$$


For infected people,

$$
\begin{aligned}
& I_{0}^{\prime}(t)=n_{2} \\
& I_{1}^{\prime}(t)=\frac{\eta n_{1} n_{2}-\mu n_{2}}{\Gamma\left(\theta_{2}+1\right)} t^{\theta_{2}} \\
& I_{2}^{\prime}(t)=\frac{\left(\eta n_{1} n_{2}-\mu n_{2}\right)\left(\eta n_{1}-\mu\right)}{\Gamma\left(2 \theta_{2}+1\right)} t^{2 \theta_{2}}-\frac{\eta^{2} n_{1} n_{2}^{2}}{\Gamma\left(\theta_{1}+\theta_{2}+1\right)} t^{\left(\theta_{1}+\theta_{2}\right)}
\end{aligned}
$$

For recovered people,

$$
\begin{aligned}
& R^{\prime}(t)_{0}=n_{3} \\
& R_{1}^{\prime}(t)=\frac{\mu n_{2}}{\Gamma\left(\theta_{3}+1\right)} t^{\theta_{3}} \\
& R_{2}^{\prime}(t)=\frac{\left(\eta n_{1} n_{2}-\mu n_{2}\right) \mu}{\Gamma\left(\theta_{2}+\theta_{3}+1\right)} t^{\left(\theta_{2}+\theta_{3}\right)}
\end{aligned}
$$

We can write the solution for fractional susceptible, Infected and recovered population as follows,

$$
\begin{aligned}
& S^{\prime}(t)=S_{0}^{\prime}(t)+S_{1}^{\prime}(t)+S_{2}^{\prime}(t)+\cdots \\
& I^{\prime}(t)=I_{0}^{\prime}(t)+I_{1}^{\prime}(t)+I_{2}^{\prime}(t)+\cdots \\
& R^{\prime}(t)=R_{0}^{\prime}(t)+R_{1}^{\prime}(t)+R_{2}^{\prime}(t)+\cdots
\end{aligned}
$$

These series are convergent in most cases. We suggest readers follow these links [29] [30] [31] to get more information about the existence and uniqueness of the results and observe the stability analysis of the solution of the fractional-order SIR model.

\section{Data-Driven Forecasting of COVID-19 Pandemic in Bangladesh}

We have fitted our data as much as possible. Being an overpopulated country, it is not easy to fit the data accurately. We have used the RMSE method and the optimization method respectively to fit our compartments [32]. We get Table 2 after fitting the data that continuously changes over time. So, it is quite difficult to keep the parameters constant. We've adopted the maximum data from the uplink [33] [34] [35]. All the data was accessed on 28 June 2021. The infection rate was low in the year 2020. However, when the so-called second wave arrives,

Table 2. Values that were used in the numerical experiment.

\begin{tabular}{ccc}
\hline Notations & Values & Data sources \\
\hline$N$ & $166,311,720$ & World meter \\
$S$ & $164,593,001$ & N-I-R \\
$I$ & 896,770 & JHU CSSE \\
$R$ & 821,949 & JHU CSSE \\
$\eta$ & 0.2386 & Estimated \\
$\mu$ & 0.0714 & Estimated \\
\hline
\end{tabular}


the number of infected people increases geometrically. It is very arduous to estimate the parameters. There are several issues to consider, including the lack of proper information, which is very common. So, we have excerpted data from some reliable sources.

\section{Sensitivity Analysis with Respect to the Basic Reproduction Number}

The local sensitivity can be described under the parameter, namely Basic Reproduction Number (BRN). BRN is the measurement of how quickly a virus spreads and can be used to predict a virus's future turning point by looking at its growth rate. The faster it grows, the more viruses will infect people and create a ghoulish situation. It will be impacted in response to some variations that may ensue in the parameters of the model. The normalization of the sensitivity index is defined as the ratio of the relative changes in variables to the relative changes in parameters. The sensitivity index is conducted to measure the most impressionable compartments in the model [36] [37] [38]. The positive signs are considered as the most sensitive to increasing the value of BRN, while those with negative signs are less sensitive to the decrease of BRN (Figure 3(a)). By definition, we may write,

$$
D_{\zeta}^{R_{0}}=\frac{\partial R_{0}}{\partial \zeta} \times \frac{\zeta}{R_{0}}
$$

where, $R_{0}$ is the Basic Reproduction Number (BRN) and $\zeta$ is elasticity index parameter. Under consideration of Caputo's fractional calculus, the basic reproduction number is defined as,

$$
R_{0}=\left(\frac{\eta}{\mu}\right)^{\theta}
$$

After some calculations, we get Table 3. It is clear that the positive concerning parameters is $\eta$. In short, any increase in $\eta$ will correspond to the increase in the probability of infecting the case, see (Figure $3(\mathrm{~b})$ ). Alongside, the negative concerning parameter is $\mu$, which indicates that an increase in the value of this parameter would favor decreasing the Coronavirus cases, see (Figure $3(\mathrm{c})$ ). Changes to the BRN are plotted in Figure 3(b) and Figure 3(c) respectively. It is observed that the BRN of Bangladesh is greater than unity when $\theta=1$ which means, the

Table 3. Sensitivity analysis parameters.

\begin{tabular}{ccc}
\hline Parameters & Elasticity & Numerical elements \\
\hline$\eta$ & $D_{\eta}^{R_{0}}$ & $+\theta$ \\
$\mu$ & $D_{\mu}^{R_{0}}$ & $-\theta$ \\
\hline (if) Values of & $R_{0}$ & \multicolumn{2}{c}{ situation } \\
\hline$R_{0}>1$ & \multicolumn{2}{c}{ It will signify the epidemics } \\
$R_{0}<1$ & & The disease will die out \\
\hline
\end{tabular}




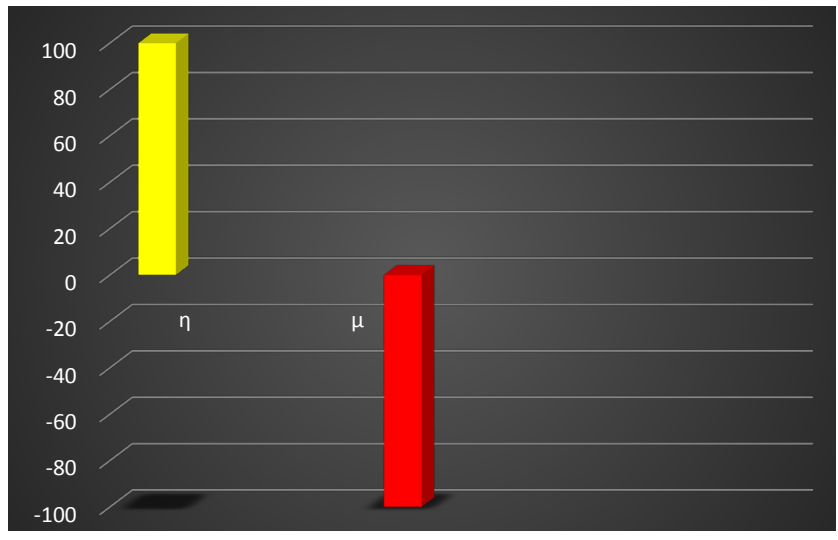

(a)

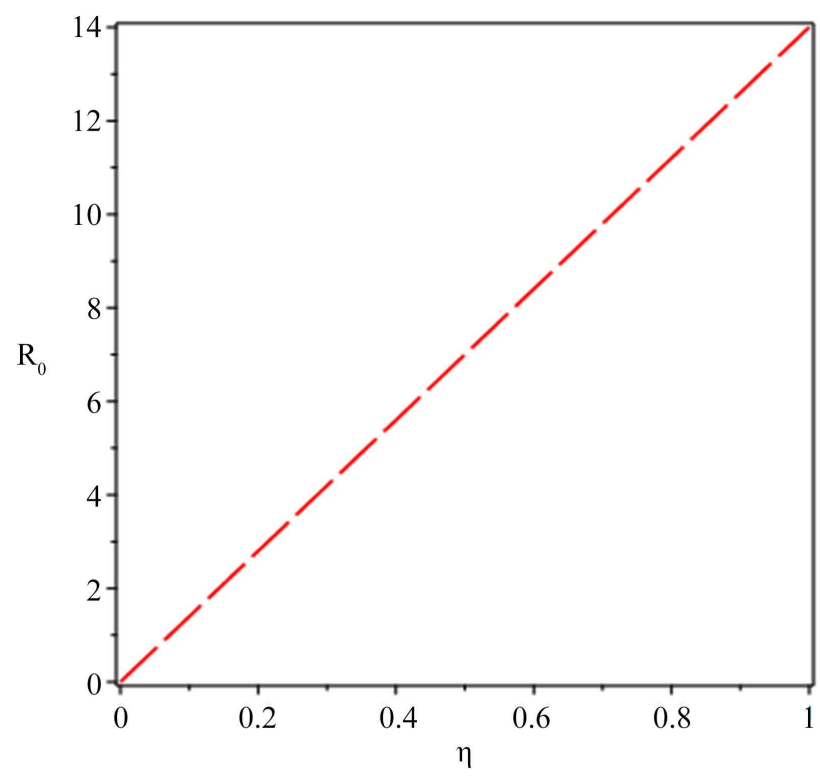

(b)

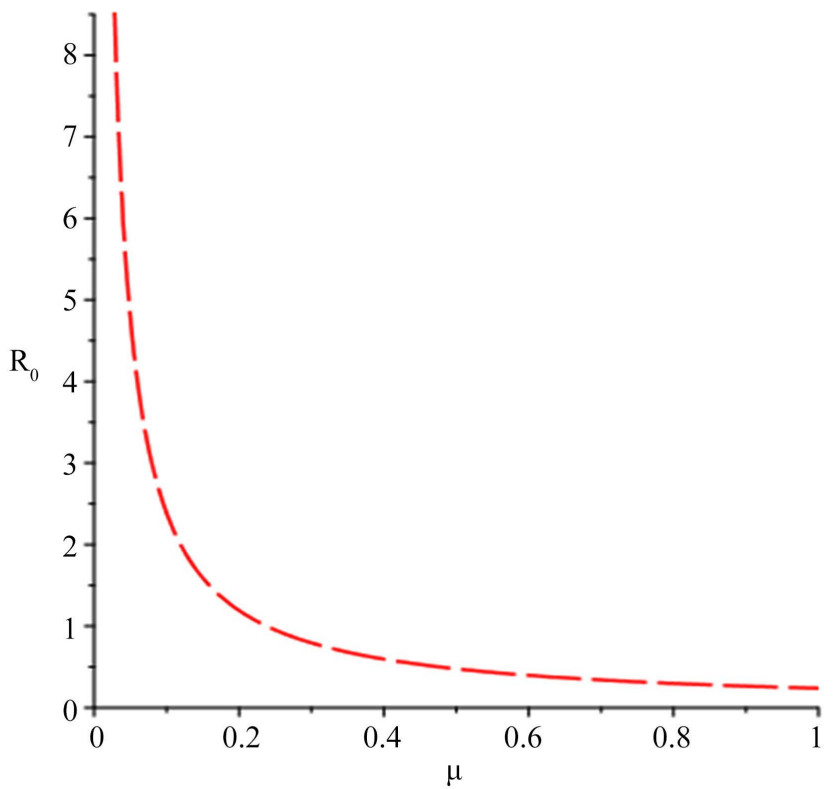

(c)

Figure 3. (a) Normalized local sensitivity indices of $R_{0}$ (Increasing with $\eta$ and Decreasing with $\mu$ ). (b) Effects of $\eta$ on $R_{0}$ (Basic Reproduction Number). (c) Effects of $\mu$ on $R_{0}$ (Basic Reproduction Number).

Coronavirus outbreaks will signify the epidemics in Bangladesh. If we take the values of $\theta$ within the range of $0<\theta \leq 1$, each calculated value of $R_{0}$ will be more than 1 .

\section{Numerical Discussions}

In this paper, the dynamical behavior of the SIR model is represented with respect to the parameters. We have got the solution of the fractional SIR model in Equation (4.16) for three different cases. We used our fitting data according to the current situation in Bangladesh. We investigated the compartment variations concerned with different values of $\theta$. The variation of the susceptible class, infected class, and recovered class are propounded in figures (Figures 4-6). Our exertion is to take a look at the next 40 days and, based on this, forecast the ultimate situation. 


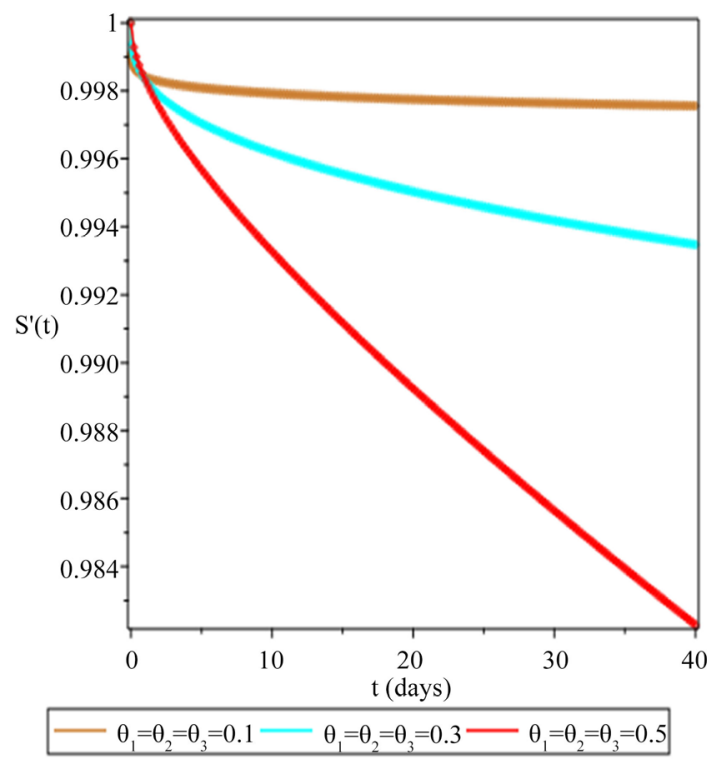

(a)

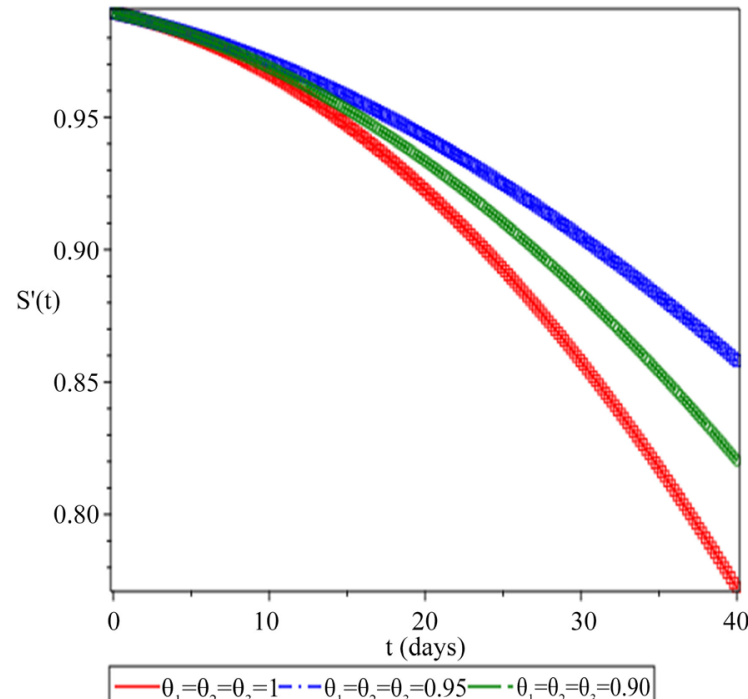

(c)

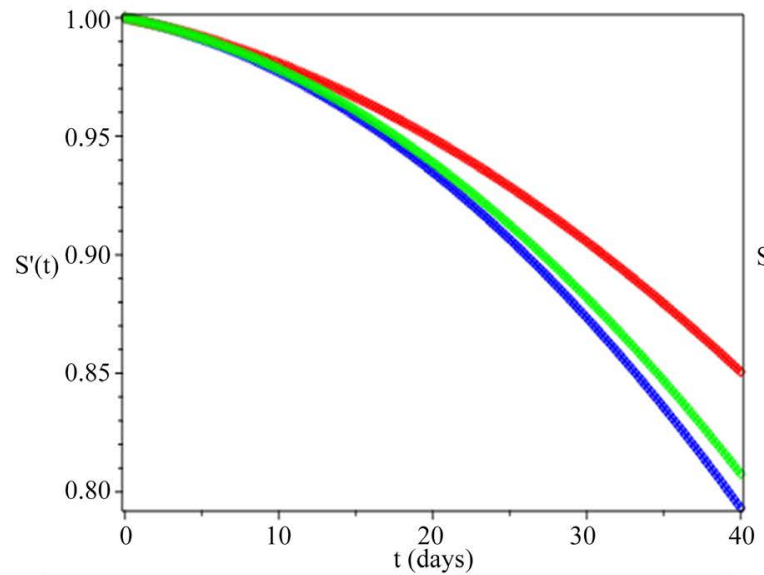

$-\theta=0.99, \theta=\theta_{0}=0.98-\theta_{1}=0.90, \theta_{2}=\theta_{3}=0.95-\theta=0.95, \theta_{2}=\theta_{3}=1$

(e)

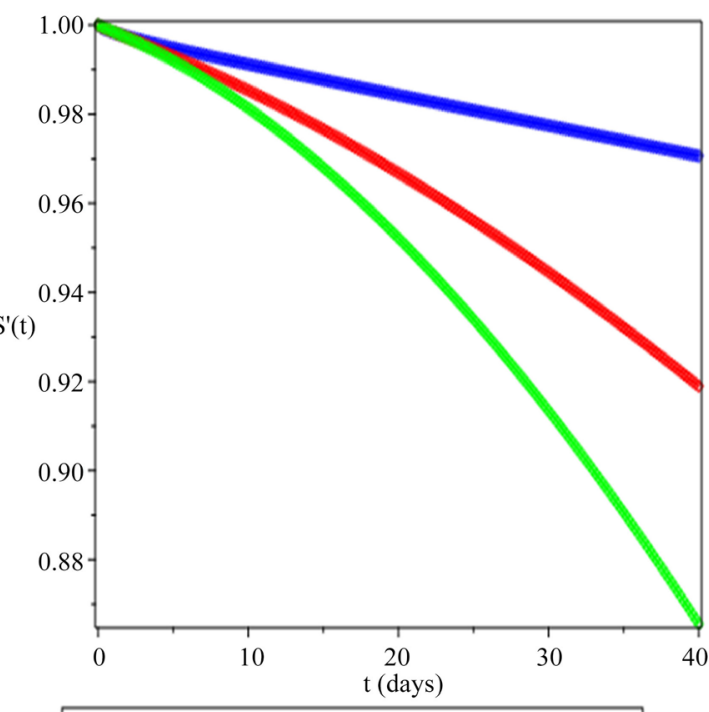

$-\theta_{1}=\theta_{2}=\theta_{3}=0.6-\theta_{1}=\theta_{2}=\theta_{3}=0.8-\theta_{1}=\theta_{2}=\theta_{3}=0.9$

(b)

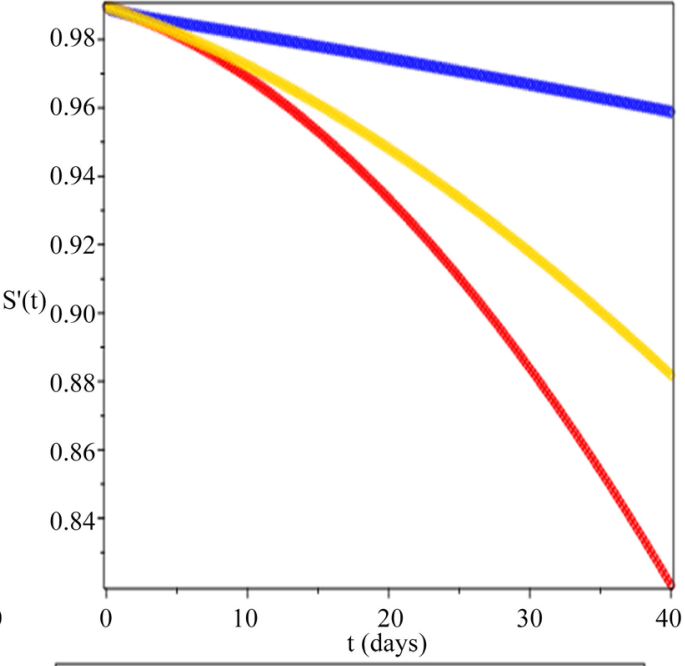

$-\theta_{1}=\theta_{2}=\theta_{3}=0.95 \diamond \theta_{1}=0.50, \theta_{2}=\theta_{3}=0.80-\theta_{1}=0.90, \theta_{2}=\theta_{3}=0.80$

(d)

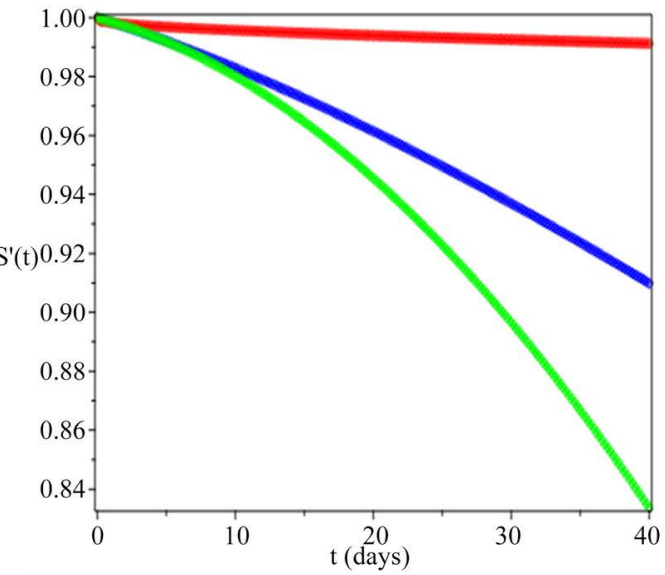

$\theta_{1}=0.95, \theta_{2}=\theta_{3}=0.6-\theta_{1}=0.30, \theta_{2}=\theta_{3}=0.50-\theta_{1}=0.90, \theta_{2}=\theta_{3}=1$

(f)

Figure 4. (a-f) Delineating the number of only susceptible people with different values of $\theta$. 


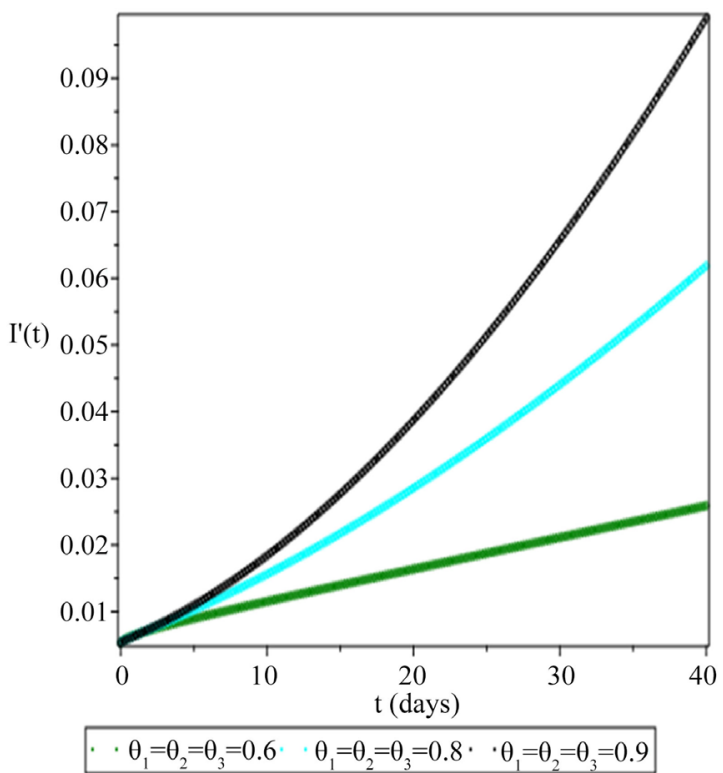

(a)

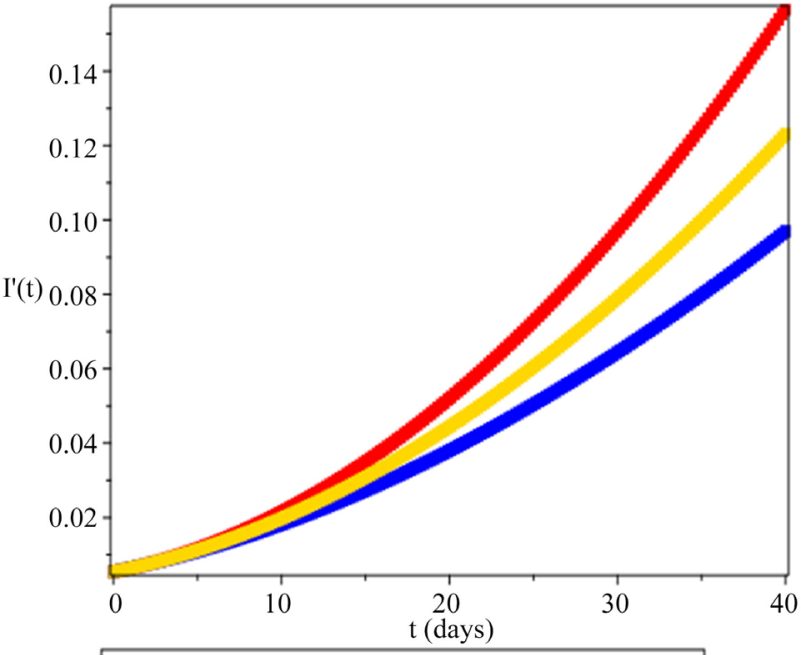

- $\theta_{1}=\theta_{2}=\theta_{3}=1$ - $\theta_{1}=\theta_{2}=\theta_{3}=0.95$ ॥ $\theta_{1}=\theta_{2}=\theta_{3}=0.9$

(c)

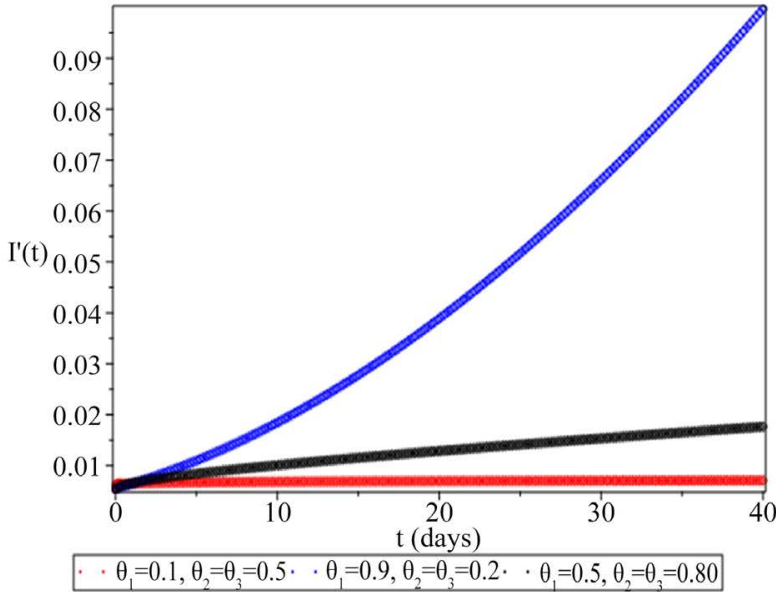

(e)

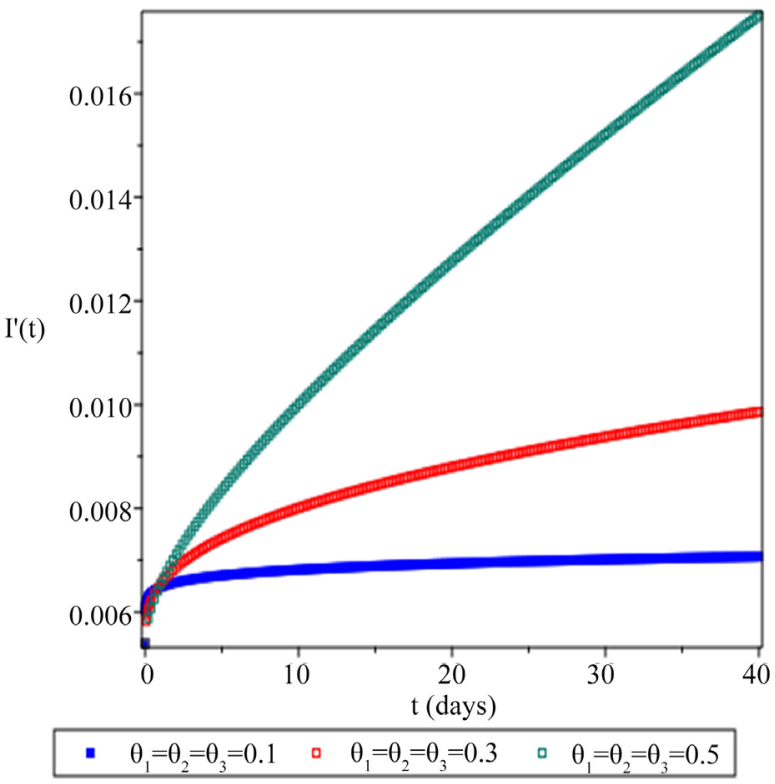

(b)

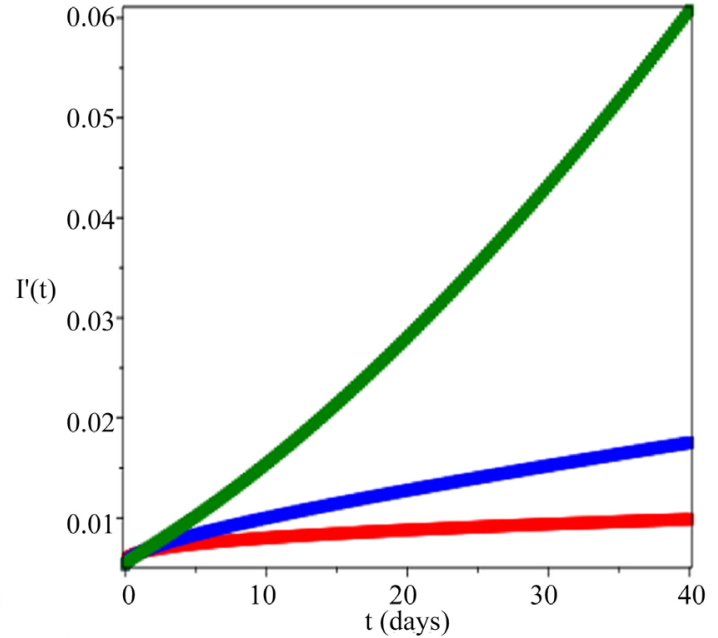

・ $\theta_{1}=0.2, \theta_{2}=\theta_{3}=0.3$ ॥ $\theta=0.4, \theta_{2}=\theta_{3}=0.5 \quad$ ॥ $\theta_{1}=0.7, \theta_{2}=\theta_{3}=0.8$

(d)

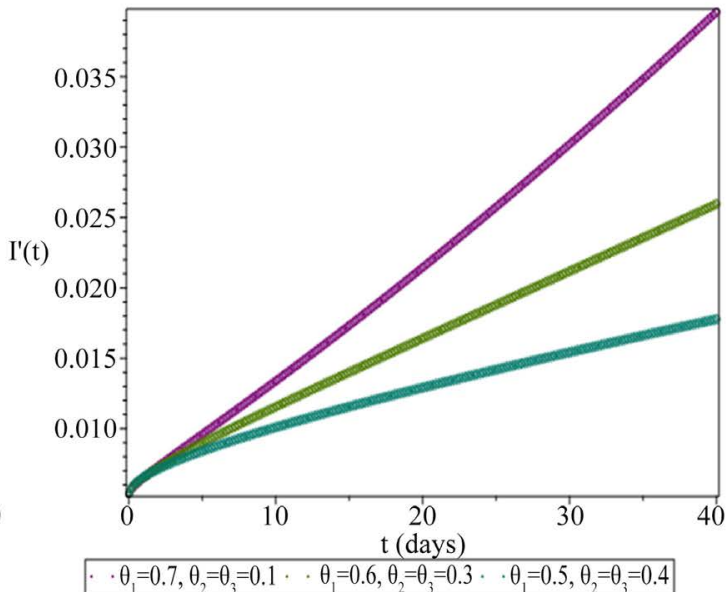

(f)

Figure 5. (a-f) Delineating the number of only infected people with different values of $\theta$. 


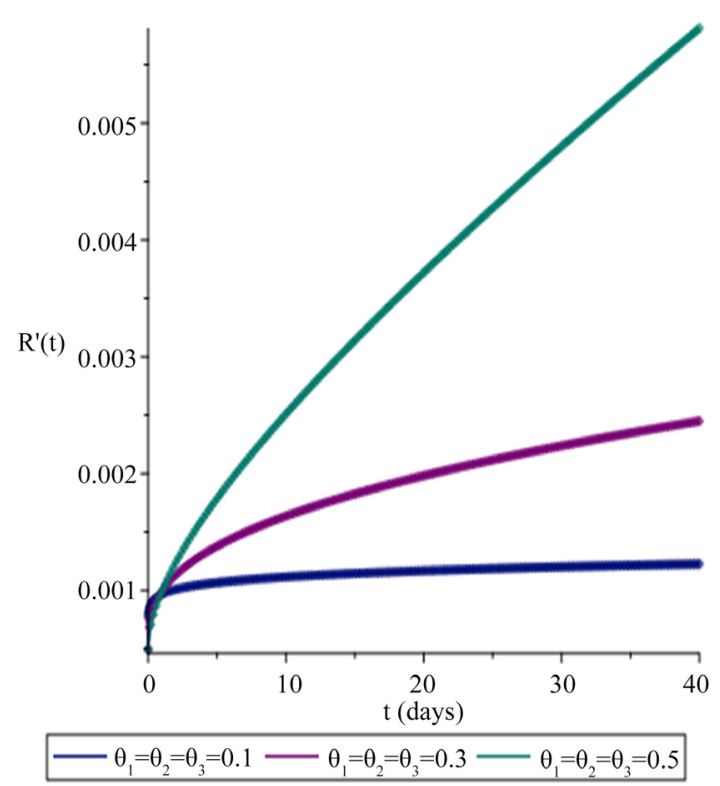

(a)

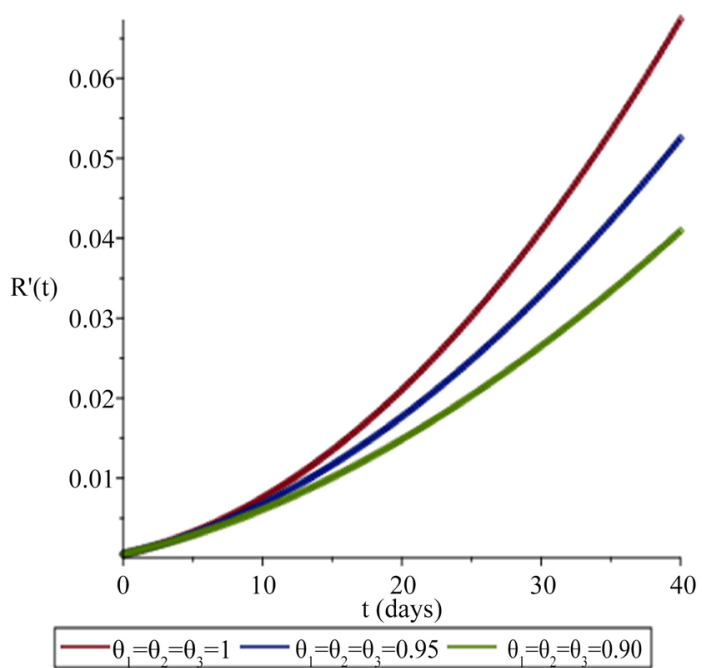

(c)

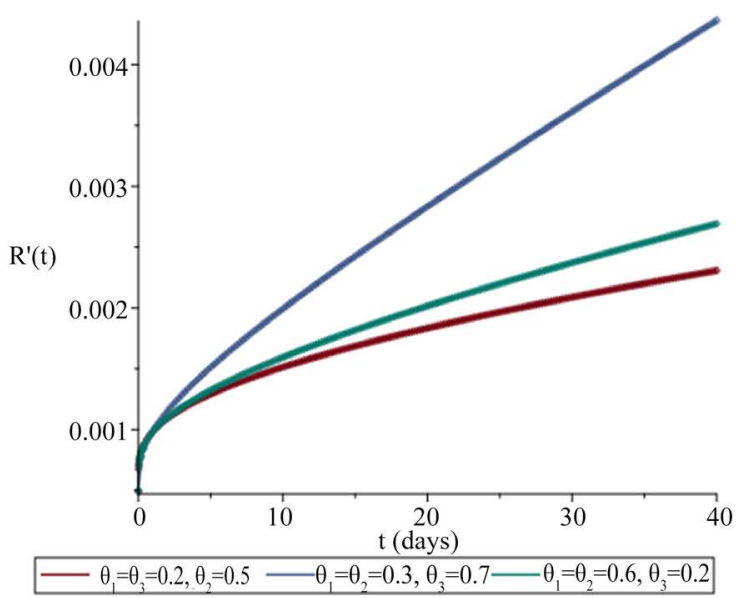

(e)

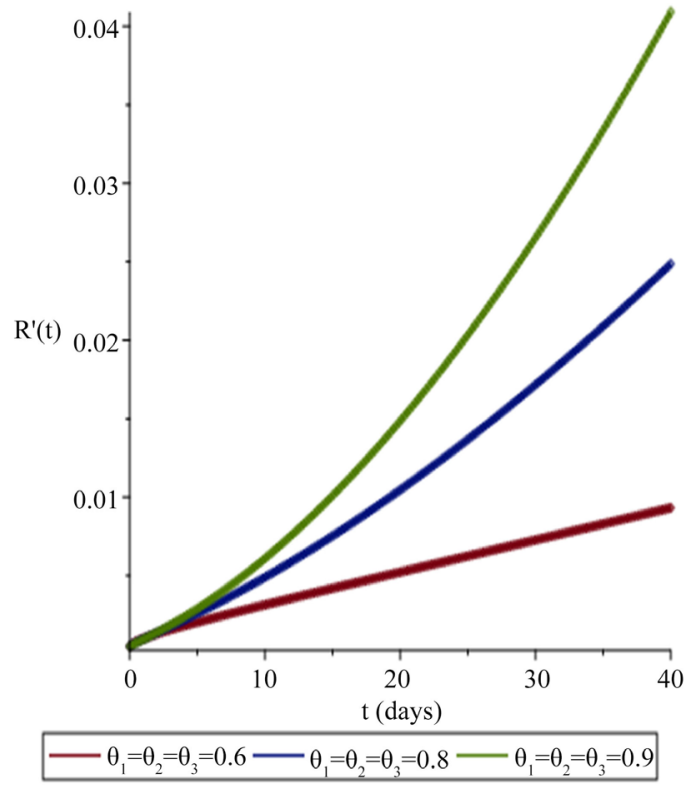

(b)

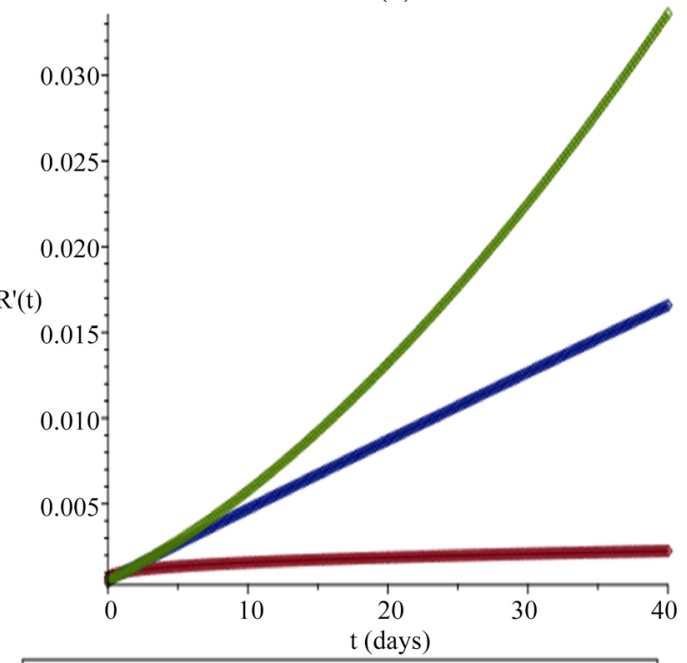

$\theta_{1}=\theta_{3}=0.3, \theta=0.2-\theta_{1}=\theta_{3}=0.1, \theta_{2}=0.95-\theta_{1}=\theta_{3}=0.8, \theta_{2}=0.9$

(d)

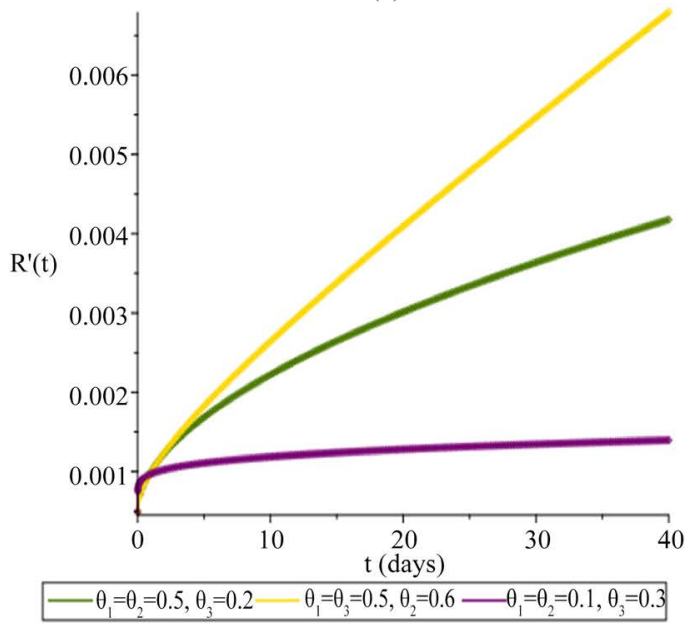

(f)

Figure 6. (a-f) Delineating the number of only recovered people with different values of $\theta$. 
As can be seen in Figure 4, the susceptible class decreases if $\theta$ increases, whereas Figure 5, shows an increase in the infectious class with increasing values of $\theta$. This makes sense because the susceptible class, after being infected, is moved to the infected section (Remark-2), thereby causing to an increase in the number of Coronavirus cases. If $\theta$ is large, the recovered population surges forward, as shown in Figure 6.

As of (Figure 4(a)), if we take the value of $\theta_{1}=\theta_{2}=\theta_{3}$ is 0.1 , the susceptible class slightly decreases with time. After that, it remains unchanged. In contrast, the recovery rate also slightly increases with time shown in (Figure 6(a)). Then, it remains steady. If we have a look at (Figure 5(a)), the features will show the same behavior as the recovered class. (Figures 5(a)-(f)), each graph illustrates that the infectious population's impact is increasing. We may expect the next few months to be even worse than the previous ones. The increasing rate of the infected class is upward. According to the current situation in Bangladesh, the number of infected people is at an all-time high, and this trend is continuing. It signifies that the number of infected population depends on the rate of infection of coronavirus outbreaks that seek a real prediction of coronavirus cases.

We observe from (Figures 6(a)-(f)), the rate of recovery is also on a sharp increase. Compared with the real scenario of Bangladesh [39] [40]. We will see that the recovery rate is increasing. Our figures indicate the same features assimilate with the substantive scenario.

The BRN is not stable for each fractional value of $\theta$. The infection rate is also increasing with the variation of BRN. When we take $\theta_{1}=0.1$ and $\theta_{2}=\theta_{3}=0.5$, the infectious number appears steady. But the real features only happen when the BRN decreases. We found the BRN number for this curve is 1.91 , which is more than 1 . It would undoubtedly increase the number of infected people, and there is a strong possibility of an epidemic in this situation too.

The number of infected people till now (24 August 2021) is $1,467,715$ and the death toll stands at 25,400 . The total number of tests according to https://www.worldometers.info/coronavirus/country/bangladesh/ is $8,686,306$ which is comparatively low compared with the population of Bangladesh. The low number of tests is one of the leading reasons for detecting COVID-19 cases. Though the number of tests is low, the probability of undetected people who are infected by the virus is higher. In our study, we found that the number of infected people is increasing at an alarming rate, which can be the most demolishing event for Bangladesh.

After analyzing Figures 4-6, we can portend that the situation is against our favor. The susceptible people are decreasing with time but infected people are increasing tremendously. An immense number of people are getting infected by the contraction of people. Infected people need more time to heal from the disease, and it asserts that reaching a stable equilibrium point is quite impossible for developing countries like Bangladesh instantly. 


\section{Conclusion}

In this paper, the fractional order SIR model with a constant sized population was solved using the Laplace Adomian Decomposition method to predict future conditions using existing data available in Bangladesh. The numerical discussion presents some exposition. The disease is rapidly spreading. Furthermore, when compared to real data, the transmission rate is extremely high. As a result, we can deduce that the situation will be more dangerous and long-lasting than before. For every $\theta$, the BRN is greater than unity, implying that an epidemic will erupt in Bangladesh with no known boundaries. The Remark-1 commentaries can also predict that a broken-down situation is about to hit Bangladesh.

A coronavirus (COVID-19) pandemic, which would primarily affect developing countries, could pose a serious threat to peace. Because there is no immunity or effective vaccine, uncontrolled transmittable contact between the infected and the susceptible can hasten the disease, as shown by our mathematical model. This discussion depicts the variation in infection and recovery rates over time. The rate of infection has a significant impact on the number of infected people. Because no effective vaccine has yet been developed, the rate of infection will continue to rise despite the increased rate of recovery.

Bangladesh is an overpopulated country with a lack of confining infrastructure in the healthcare system and proper utilization of knowledge about the virus among the people. It matters to us that if people don't follow the provision of outbreaks, the infection rate will definitely increase. Our numerical simulations suggest that the epidemic can effectively be controlled only if its contact rate is lowered, and this is only possible when people follow rules like social distancing, wearing protective masks, using hand-sanitization, etc.

\section{Acknowledgements}

The authors would like to thank the referees for giving some valuable instructions to improve this paper. And special thanks to our beloved cat "Jaye" for helping us to think about this paper.

\section{Conflicts of Interest}

The authors declare no conflicts of interest regarding the publication of this paper.

\section{References}

[1] World Health Organization (2020) WHO Director-General's Opening Remarks at the Media Briefing on COVID-19 11 March 2020.

[2] World Health Organization (2020) WHO Director-General's Opening Remarks at the Media Briefing on COVID-19 11 March 2020. WHO Director General's Speeches. Geneva.

[3] Zhu, N., Zhang, D., Wang, W., et al. (2020) A Novel Coronavirus from Patients with Pneumonia in China, 2019. The New England Journal of Medicine, 382, 
727-733. https://doi.org/10.1056/NEJMoa2001017

[4] Peeri, N.C., Shrestha, N., Rahman, M.S., Zaki, R., Tan, Z., Bibi, S., et al. (2020) The SARS, MERS and Novel Coronavirus (COVID-19) Epidemics, the Newest and Biggest Global Health Threats: What Lessons Have We Learned? International Journal of Epidemiology, 49, 717-726. https://doi.org/10.1093/ije/dyaa033

[5] Cui, J., Li, F. and Shi, Z.L. (2019) Origin and Evolution of Pathogenic Coronaviruses. Nature Reviews Microbiology, 17, 181-192. https://doi.org/10.1038/s41579-018-0118-9

[6] Fenton, M.B., Mubareka, S., Tsang, S.M., Simmons, N.B. and Becker, D.J. (2020) COVID-19 and Threats to Bats. FACETS, 5, 349-352.

https://doi.org/10.1139/facets-2020-0028

[7] Balboni, A., Battilani, M. and Prosperi, S. (2012) The SARS-Like Coronaviruses: The Role of Bats and Evolutionary Relationships with SARS Coronavirus. New Microbiologica, 35, 1-16. https://doi.org/10.1100/2012/989514

[8] Sun, Z., Thilakavathy, K., Kumar, S.S., He, G. and Liu, S.V. (2020) Potential Factors Influencing Repeated SARS Outbreaks in China. International Journal of Environmental Research and Public Health, 17, 1633.

https://doi.org/10.3390/ijerph17051633

[9] Zhou, Y., Shi, X., Fu, W., Xiang, F., He, X., Yang, B., Wang, X. and Ma, W.L. (2021) Gut Microbiota Dysbiosis Correlates with Abnormal Immune Response in Moderate COVID-19 Patients with Fever. Journal of Inflammation Research, 14, 2619 2631. https://doi.org/10.2147/JIR.S311518

[10] Islam, M.A., Alam, S.S., Kundu, S., Hossan, T., Kamal, M.A. and Cavestro, C. (2020) Prevalence of Headache in Patients with Coronavirus Disease 2019 (COVID-19): A Systematic Review and Meta-Analysis of 14,275 Patients. Frontiers in Neurology, 11, Article ID: 562634. https://doi.org/10.3389/fneur.2020.562634

[11] Saniasiaya, J., Islam, M.A. and Abdullah, B. (2020) Prevalence and Characteristics of Taste Disorders in Cases of COVID-19: A Meta-Analysis of 29,349 Patients. Otolaryngology_Head and Neck Surgery, 165, 33-42. https://doi.org/10.1177/0194599820981018

[12] Gupta, S., Raghuwanshi, G.S. and Chanda, A. (2020) Effect of Weather on COVID-19 Spread in the US: A Prediction Model for India in 2020. Science of the Total Environment, 728, Article ID: 138860. https://doi.org/10.1016/j.scitotenv.2020.138860

[13] Rana, M.S., Rony, M.A.T., Aktar, N., Hossain, K., Shuvo, T.A., Begum, S. and Hosna, A.U. (2021) Effect of COVID-19 in Bangladesh: Challenge and Overcome. Journal of Applied Science, Engineering, Technology, and Education, 3, 53-68. https://doi.org/10.35877/454RI.asci128

[14] Daria, S. and Islam, M.R. (2021) The Second Wave of COVID-19 Pandemic in Bangladesh: An Urgent Call to Save Lives. Asia-Pacific Journal of Public Health. https://doi.org/10.1177/10105395211021686

[15] Islam, M.T., Talukder, A.K., Siddiqui, M.N. and Islam, T. (2020) Tackling the COVID-19 Pandemic: The Bangladesh Perspective. Journal of Public Health Research, 9, 1794. https://doi.org/10.4081/jphr.2020.1794

[16] Anwar, S., Nasrullah, M. and Hosen, M.J. (2020) COVID-19 and Bangladesh: Challenges and How to Address Them. Frontiers in Public Health, 8, 154. https://doi.org/10.3389/fpubh.2020.00154

[17] Chandrow, O. (2021) Forecasting COVID-19 Pandemic in Bangladesh by Using 
Homotopy Perturbation Method. IOSR Journal of Mathematics (IOSR-JM), 17, 5-12.

[18] Saha, S., Tanmoy, A.M., Hooda, Y., Tanni, A.A., Goswami, S., Al Sium, S.M., Saha, S.K., et al. (2021) COVID-19 Rise in Bangladesh Correlates with Increasing Detection of B. 1.351 Variant. BMJ Global Health, 6, e006012.

https://doi.org/10.1136/bmjgh-2021-006012

[19] Rahman, S.H., Razzaque, A.B., Rahman, J.I. and Shadat, W.B. (2020) Socio-Economic Impact of COVID-19 and Policy Implications for Bangladesh. BRAC Institute of Governance and Development (BIGD), Dhaka.

[20] Women, U.N. and Snyder, D. (2020) COVID-19 and the Care Economy: Immediate Action and Structural Transformation for a Gender-Responsive Recovery. Gender and COVID-19 Policy Brief Series. UN Women, New York.

[21] Sarker, M.M.R. and Fagun, A.N. (2021) COVID-19, Food Security, Food Prices and Urban-Rural Interrelationship for Sustainable Food and Nutritional Security: A Study on Dhaka City. International Journal of Agricultural Economics, 6, 47.

[22] Harir, A., Malliani, S. and Chandli, L.S. (2021) Solutions of Conformable Fractional-Order SIR Epidemic Model. International Journal of Differential Equations, 2021, Article ID: 6636686. https://doi.org/10.1155/2021/6636686

[23] Kermack, W.O. and McKendrick, A.G. (1927) A Contribution to the Mathematical Theory of Epidemics. Proceedings of the Royal Society of London. Series A, Containing Papers of a Mathematical and Physical Character, 115, 700-721. https://doi.org/10.1098/rspa.1927.0118

[24] Rida, S.Z., Arafa, A.A.M. and Gaber, Y.A. (2016) Solution of the Fractional Epidemic Model by L-ADM. Journal of Fractional Calculus and Applications, 7, 189-195.

[25] Podlubny, I. (1998) Fractional Differential Equations: An Introduction to Fractional Derivatives, Fractional Differential Equations, to Methods of Their Solution and Some of Their Applications. Elsevier, Amsterdam.

[26] Shah, R., Khan, H., Arif, M. and Kumam, P. (2019) Application of Laplace-Adomian Decomposition Method for the Analytical Solution of Third-Order Dispersive Fractional Partial Differential Equations. Entropy, 21, 335.

https://doi.org/10.3390/e21040335

[27] Mohamed, M.Z. and Elzaki, T.M. (2018) Comparison between the Laplace Decomposition Method and Adomian Decomposition in Time-Space Fractional Nonlinear Fractional Differential Equations. Applied Mathematics, 9, 448-458. https://doi.org/10.4236/am.2018.94032

[28] Khan, H., Shah, R., Kumam, P., Baleanu, D. and Arif, M. (2020) Laplace Decomposition for Solving Nonlinear System of Fractional Order Partial Differential Equations. Advances in Difference Equations, 2020, Article No. 375. https://doi.org/10.1186/s13662-020-02839-y

[29] Albadarneh, R.B., Batiha, I.M., Ouannas, A. and Momani, S. (2021) Modeling COVID-19 Pandemic Outbreak Using Fractional-Order Systems. Computer Science, 16, 1405-1421.

[30] Zaman, G. and Jung, I.H. (2007) Stability Techniques in SIR Epidemic Models. PAMM: Proceedings in Applied Mathematics and Mechanics, 7, 2030063-2030064. https://doi.org/10.1002/pamm.200701147

[31] Kumar, A. and Nilam (2018) Stability of a Time Delayed SIR Epidemic Model along with Nonlinear Incidence Rate and Holling Type-II Treatment Rate. International Journal of Computational Methods, 15, Article ID: 1850055. 
https://doi.org/10.1142/S021987621850055X

[32] Kozioł, K., Stanisławski, R. and Bialic, G. (2020) Fractional-Order Sir Epidemic Model for Transmission Prediction of Covid-19 Disease. Applied Sciences, 10, 8316. https://doi.org/10.3390/app10238316

[33] COVID, C. (2021) Global Cases by Johns Hopkins CSSE.

[34] Worldometer, D. (2020) COVID-19 Coronavirus Pandemic. World Health Organization, Geneva. https://www.worldometers.info

[35] Worldometer, S. (2020) Covid-19 Coronavirus Pandemic: Worldometer.

[36] Van den Driessche, P. (2017) Reproduction Numbers of Infectious Disease Models. Infectious Disease Modelling, 2, 288-303. https://doi.org/10.1016/j.idm.2017.06.002

[37] Shah, N.H., Suthar, A.H., Jayswal, E.N. and Sikarwar, A. (2021) Fractional SIR-Model for Estimating Transmission Dynamics of COVID-19 in India. J, 4, 86-100. https://doi.org/10.3390/j4020008

[38] Alshomrani, A.S., Ullah, M.Z. and Baleanu, D. (2021) Caputo SIR Model for COVID-19 under Optimized Fractional Order. Advances in Difference Equations, 2021, Article No. 185. https://doi.org/10.1186/s13662-021-03345-5

[39] Covid, B. (2020) Update. Institute of Epidemiology, Disease Control and Research (IEDCR).

[40] Institute of Epidemiology, Disease Control and Research. General Information COVID-19 2021. 